\title{
Psychogenic Foreign Accent Syndrome: A New Case
}

\author{
Stefanie Keulen ${ }^{1,2}$, Jo Verhoeven ${ }^{3,4}$, Louis De Page ${ }^{5}$, Roel Jonkers ${ }^{2}$, Roelien Bastiaanse ${ }^{2}$ \\ and Peter Mariën ${ }^{1,6 *}$ \\ ' Department of Linguistics and Literary Studies, Clinical and Experimental Neurolinguistics, Vrije Universiteit Brussel, \\ Brussels, Belgium, ${ }^{2}$ Department of Linguistics, Center for Language and Cognition Groningen, Rijksuniversiteit Groningen, \\ Groningen, Netherlands, ${ }^{3}$ Department of Language and Communication Science, School of Health, City University London, \\ London, UK, ${ }^{4}$ Department of Linguistics, Computational Linguistics and Psycholinguistics Research Center, Universiteit \\ Antwerpen, Antwerp, Belgium, ${ }^{5}$ Department of Psychology, Faculty of Psychology and Educational Sciences, Vrije \\ Universiteit Brussel, Brussels, Belgium, ${ }^{6}$ Department of Neurology and Memory Clinic, ZNA Middelheim General Hospital, \\ Antwerp, Belgium
}

OPEN ACCESS

Edited by:

Srikantan S. Nagarajan, University of California, San Francisco,

USA

Reviewed by:

Katia Nemr,

University of São Paulo, Brazil Stéphane Poulin,

Université Laval, Canada

*Correspondence:

Peter Mariën

peter.mariën@vub.ac.be

Received: 26 June 2015 Accepted: 21 March 2016 Published: 19 April 2016

Citation:

Keulen S, Verhoeven J, De Page L, Jonkers $R$, Bastiaanse $R$ and Mariën $P$ (2016) Psychogenic Foreign Accent Syndrome: A New Case.

Front. Hum. Neurosci. 10:143. doi: 10.3389/fnhum.2016.00143
This paper presents the case of a 33-year-old, right-handed, French-speaking Belgian lady who was involved in a car accident as a pedestrian. Six months after the incident she developed a German/Flemish-like accent. The patient's medical history, the onset of the FAS and the possible psychological causes of the accent change are analyzed. Relevant neuropsychological, neurolinguistic, and psychodiagnostic test results are presented and discussed. The psychodiagnostic interview and testing will receive special attention, because these have been underreported in previous FAS case reports. Furthermore, an accent rating experiment was carried out in order to assess the foreign quality of the patient's speech. Pre- and post-morbid spontaneous speech samples were analyzed phonetically to identify the pronunciation characteristics associated with this type of FAS. Several findings were considered essential in the diagnosis of psychogenic FAS: the psychological assessments as well as the clinical interview confirmed the presence of psychological problems, while neurological damage was excluded by means of repeated neuroimaging and neurological examinations. The type and nature of the speech symptoms and the accent fluctuations associated with the patient's psychological state cannot be explained by a neurological disorder. Moreover, the indifference of the patient toward her condition may also suggest a psychogenic etiology, as the opposite is usually observed in neurogenic FAS patients.

Keywords: foreign accent syndrome, psychogenic FAS, speech disorder, psychodiagnostics, accent attribution experiment, accent rating experiment

\section{INTRODUCTION}

Foreign accent syndrome (FAS) is a rare motor speech disorder which causes patients to speak their native language with an accent which is perceived as non-native by speakers of the same speech community. This "non-nativeness" is the result of suprasegmental and/or segmental changes, which-according to the criteria proposed by Whitaker (1982)-are the consequence of damage to the central nervous system. Often, the etiology is stroke or brain trauma affecting the language dominant areas of the brain, e.g., the left (pre)frontal, temporal and/or parietal region, the rolandic and perisylvian area, as well as the insular region. Nevertheless, FAS has also been associated with other etiologies including MS (Villaverde-Gonzalález et al., 2003; Bakker et al., 2004; Chanson et al., 2009), neoplasms 
(Abel et al., 2009; Masao et al., 2011; Tomasino et al., 2013) and vascular dementia (Paquier and Assal, 2007). Verhoeven and Mariën (2010) argue that FAS is not only caused by (acute) neurological damage but it can also result from psychogenic issues. In psychogenic FAS, the accent is associated with a psychological/psychiatric disorder. Furthermore, Verhoeven and Mariën (2010) also identified a mixed type in which FAS initially develops on the basis of a neurological disorder: this affects patients so profoundly that they further develop the accent in order to create the impression of a more authentic personality.

The current study focuses on psychogenic FAS. For most of the psychogenic cases reported so far, a psychogenic cause was assumed because it was not possible to unambiguously identify a neurological disorder. Some authors have discarded the idea of psychogenic FAS because of diagnostic difficulties to objectify this condition (Gurd et al., 2001; Poulin et al., 2007). In some patients diagnosed with psychogenic FAS (repeated) brain imaging with CT or MRI revealed structural damage, but the speech problems were disproportionate in relation to the damage. Furthermore, in the majority of the psychogenic FAS cases symptoms were fluctuating, increasing in certain (social/emotional) contexts, diminishing or even completely resolving in others (e.g., Van Borsel et al., 2005; Tsuruga et al., 2008; Haley et al., 2010; Jones et al., 2011). Such a atypical fluctuating course of symptoms is typical of speech and voice disorders of psychogenic origin (Avbersek and Sisodiya, 2010). When FAS is typified by these phenomena and associated with identifiable psychological problems (e.g., depression, familial history, suicidal ideation) a non-organic origin may be expected (Roth et al., 1989; Tippett and Siebens, 1991; Baumgartner and Duffy, 1997; Baumgartner, 1999).

\section{BACKGROUND}

In little over a century-counting from the first (anecdotal) FAS description by Pierre Marie in 1907 until July of 2014-only 15 FAS cases with a presumed psychogenic origin have been reported (Critchley, 1962; Gurd et al., 2001; Reeves and Norton, 2001; Van Borsel et al., 2005; Verhoeven et al., 2005; Poulin et al., 2007; Roy et al., 2012, case 1; Reeves et al., 2007; Tsuruga et al., 2008; Cottingham and Boone, 2010; Haley et al., 2010; Jones et al., 2011; Lewis et al., 2013; Polak et al., 2013). This study presents a new case of psychogenic FAS. Neuropsychological testing was carried out to assess a wide range of cognitive functions. The psychological state of the patient was evaluated by means of a series of psychodiagnostic tests, including symptom validity tests. Extensive neuropsychological investigations (Verhoeven et al., 2005; Poulin et al., 2007; Haley et al., 2010) and psychodiagnostic testing (Verhoeven et al., 2005; Cottingham and Boone, 2010) have only been occasionally reported in psychogenic case reports, although such an in-depth investigation is crucially important for accurate diagnosis and successful therapy (see also: MorenoTorres et al., 2013). In addition, a perceptual analysis of the patient's most salient speech characteristics was carried out and an accent rating experiment was run to find out to what extent the patient's accent was considered as non-native. Additionally, the listening panel was asked to indicate the mother tongue of the FAS speaker. Such experiments have previously only been reported in four other studies (Di Dio et al., 2006; Kanjee et al., 2010; Verhoeven et al., 2013: rating and attribution experiment; Dankovičová and Hunt, 2011: rating experiment). We are convinced that perceptual assessment reinforces the diagnosis of FAS and it may provide new insights into the perceptual impression(s) created by FAS in the ear of the beholder (Verhoeven et al., 2013).

The patient gave written informed consent to report the medical data. All the tests reported below are part of the standard, clinical neurolinguistic work-up in patients with speech and language disorders at ZNA Middelheim general hospital. Speech recordings were also made to allow for better follow-up. The patient gave written consent to use recorded speech samples for the perceptual evaluation in a public environment.

\section{Case Presentation and Medical History}

$\mathrm{SB}$ is a 33-year-old, right-handed, monolingual Frenchspeaking lady, originating from a village in the francophone Walloon part of Belgium near the Flemish border. She was raised in French and her parents were monolingual Frenchspeaking Belgians. From a neurological perspective, growth and development were unremarkable. There was no family history of neurodevelopmental disorders or learning disabilities. She had always obtained normal school results and had an educational level of 12 years. She consulted the neurology department in November 2013 because of a "Dutch or German-like accent," which she acutely developed approximately 6 months after she was hit by a car while crossing the street to deliver orders from the bakery where she worked as a saleswoman. A few months after the accident occurred, the patient mentioned an "abrupt change of personality." She considered her behavioral change as the cause for her sudden dismissal at work. There had been serious disagreements with colleagues, customers, as well as with her line manager. She was dismissed in June 2012. It was shortly after her dismissal that she developed a foreign accent.

The accident happened in December 2011. There had been no loss of consciousness. Apart from some superficial subcutaneous hematomas in the frontal and right peri-orbital region, clinical examination on admission to the hospital was normal. CT scan of the brain and spinal cord were normal. A diagnosis of minor head trauma was made. One week later, the patient started suffering from increasingly painful headaches (possibly a post-traumatic migraine, see: Weiss et al., 1991) and a desensitization of the scalp. She complained of vertigo and was hospitalized for 3 days. The clinical neurological examination on admission was normal. Laboratory investigations (blood and urine), EEG and CT were normal as well. She was diagnosed with a post-concussion syndrome, benign paroxysmal vertigo (positive Hallpike test) and a cervical trauma. Approximately 1 month later the symptoms were still present. She identified several regions of hyperaesthesia and anesthesia in the facial area and the scalp. The vertigo had receded, but she complained of severe neck and shoulder pain. Approximately 4 months after the accident, she consulted a neurologist again. The clinical neurological examination and EEG revealed no abnormalities. During this visit, the patient 
mentioned that she felt she had become "someone else" after the accident, with regular aggressive outbursts toward family, friends, strangers, and clients. The patient complained about attention deficits and permanent fatigue. She also mentioned that the intensity of the accent was fluctuating: the accent was heavier when she was tired.

Due to the persistence of her complaints with respect to her accented speech and memory, the patient was referred to hospital for additional radiological examinations. In November 2012, she underwent a saggital T1-weighted and axial FLAIR, diffusion, SWI, proton density and T2-weighted MRI of the head, a coronal FLAIR MRI perpendicular to the axes of the left and right hippocampi, as well as an angio-MRI of the brain and 3D TOF of the circle of Willis. The qualified radiologist reported that all acquisitions were normal.

In November 2013, she consulted our department because of the persistence of the accent change and cognitive complaints (attention problems and episodes of confusion). At a linguistic level she suffered from word-finding difficulties and morphological problems related to article-noun agreement (she did not differentiate between the masculine and feminine forms of the definite article). According to her, listeners had the impression that she spoke with a Dutch accent. Her previous customers, for instance, had perceived her as a native Dutchspeaking Belgian and repeatedly asked her why she spoke French instead of "Flemish" (the Belgian variant of Dutch; see: Verhoeven, 2005). She still suffered from behavioral changes and avoided social contact with her family and friends because of a lack of interest on her part. Yet, she was looking for more excitement in life, as well as a more frivolous, out-going lifestyle. She said she was deeply bored. In addition, a number of depressive symptoms were mentioned including apathy, loss of drive and initiative, and mood-swings.

\section{Neuropsychological Testing}

The first neuropsychological assessments were carried out approximately 1 year after the accident in January 2012 (see Table 1 for an overview of the results). The test battery consisted of the Wechsler Adult Intelligence Scale-IV (WAIS-IV; Wechsler, 2011, French Ed.), the d2-test (Brickenkamp and Zillmer, 1998), the "Barrage de Zazzo" (Zazzo, 1974), the Stroop Test (Stroop, 1935), the Wisconsin Card Sorting Test (WCST; Grant and Berg, 1948), and the California Verbal Learning Task (CVLT, Delis et al., 2000). Repeated neuropsychological testing in 2014 consisted of the Wechsler Memory Scale-Revised (Wechsler, 1987), the Boston Naming Test (Kaplan et al., 1983); the Trail Making Test (Reitan, 1958), and the d2-test.

A full scale IQ (FSIQ) of 105 was found with a significant discrepancy of 24 IQ-points between the verbal (96) and performance IQ level (120). All subtest scores were within the normal range. Executive function (mental flexibility, frontal problem solving) was tested by means of the Stroop and the WCST. She obtained a normal result on the WCST, but depressed scores on the Stroop with slowed processing in the color naming condition (Z-score $=-1.5 \mathrm{SD}$ ), interference condition (Z-score $=-1,6 \mathrm{SD}$ ), and flexibility condition (Z-score = $-1.7 \mathrm{SD})$. Tests measuring sustained visuo-motor and selective attention (d2-test in 2012/2014 and the "test de barrage de Zazzo") were performed at a slow pace. Scores for total items treated for the d2-test (2012: $Z=-3.08 \mathrm{SD}$; 2014: $Z=-2.44$ SD) as well as the total items corrected (2012: $Z=-2.94 \mathrm{SD}$; 2014: $Z=-2.20 \mathrm{SD}$ ) were in the pathological range. As shown by the CVLT, verbal memory was intact, the patient obtained borderline results for the "total recollection" (5 trials) of List A $(\mathrm{Z}$-score $=-1.49 \mathrm{SD})$. On other subtasks of the CVLT she obtained normal results ( +1 SD: Cued recall A, Delayed recall A, Cued delayed recall A, Recognition).

In 2014, a significant discrepancy between a very superior visual memory index $(=133)$ and clinically deficient verbal memory index $(=74 ;-1.7 \mathrm{SD})$ was found on the WMS-R. As reflected by a general attention index of 70 ( -2 SD), the WMS-R tasks scores were in the deficient range. The Trail Making Test (part A and B) disclosed low average visual search (< pct. 10) and mental flexibility (pct. 20). Sustained visuo-motor attention scores were within the defective range. Performance on the BNT was normal. Overall, the data for the test session in 2014 were in line with the results obtained in 2012.

\section{Psychodiagnostic Assessment}

The psychodiagnostic assessment consisted of an interview with an experienced clinical psychologist (LDP), which was followed some time later by a session during which the patient was asked to respond to a series of standardized questionnaires. These questionnaires were completed at the hospital, without the help of the examiner. Testing included the Minnesota Multiphasic Personality Inventory-2 (MMPI-2: Butcher et al., 1989); the Defense Style Questionnaire (DSQ-60: Thygesen et al., 2008); the Rotter Incomplete Sentences Blank (RISB-FR: Rotter et al., 1992); Beck Depression Inventory-II (BDI-2: Beck et al., 1996), Pathological Narcissism Inventory (PNI: Pincus et al., 2009; French version: Diguer et al., 2014), and the Narcissistic Personality Inventory-40 (NPI-40: Raskin and Hall, 1979).

Furthermore, symptom validity and self-presentation tests were carried out by means of the List of Indiscriminate Psychopathology (LIPP: Merten and Stevens, 2012), and the Supernormality Scale (SS: Cima et al., 2003). The LIPP is an experimental questionnaire, which measures calibration problems. It consists of questions addressing pseudo- and real symptoms (Merckelbach et al., 2013). Malingering participants are in doubt as to which symptoms they can report and which ones they cannot. The SS is a questionnaire, which evaluates deception or denial under the guise of giving socially desirable answers (Cima et al., 2003).

During intake the patient gave evidence of disinhibition which mainly manifested itself as laughing without reason, Witzelsücht and inappropriate comments. The patient was reticent and maintained a (psychologically immature) defensive attitude throughout the entire interview. Her thoughts were preoccupied by frustration about her own situation. The interview was dominated by her feelings concerning her increased impulsiveness, aggressiveness and apathetic demeanor vis-à-vis her family, former boss, and colleagues. The examiner noticed that a topic which rendered her frustrated led to an emotional breakthrough during which she lost the 
TABLE 1 | Neuropsychological test results for the years 2012 and 2014.

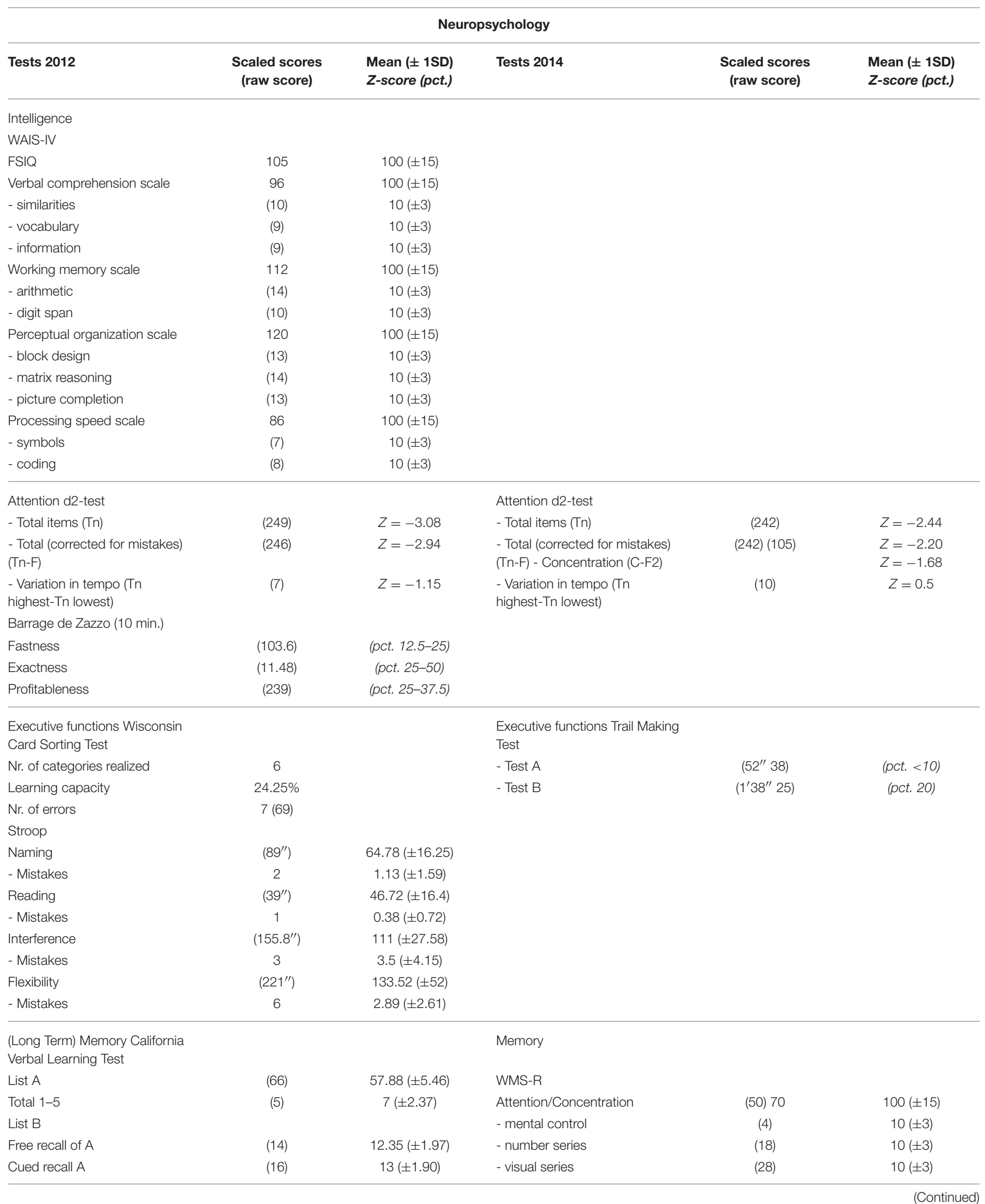




\begin{tabular}{|c|c|c|c|c|c|}
\hline \multicolumn{6}{|c|}{ Neuropsychology } \\
\hline Tests 2012 & $\begin{array}{l}\text { Scaled scores } \\
\text { (raw score) }\end{array}$ & $\begin{array}{l}\text { Mean ( } \pm \text { 1SD) } \\
\text { Z-score (pct.) }\end{array}$ & Tests 2014 & $\begin{array}{l}\text { Scaled scores } \\
\text { (raw score) }\end{array}$ & $\begin{array}{l}\text { Mean ( } \pm \text { 1SD) } \\
\text { Z-score (pct.) }\end{array}$ \\
\hline Delayed recall A & (15) & $13( \pm 1.84)$ & Visual Memory & (66) 133 & $100( \pm 15)$ \\
\hline Cued delayed recall A & (16) & $13.59( \pm 1.91)$ & - perceptual memory & (7) & $10( \pm 3)$ \\
\hline \multirow[t]{7}{*}{ Recognition } & (16) & $14.71( \pm 1.40)$ & - associated visual pairs & (18) & $10( \pm 3)$ \\
\hline & & & Verbal Memory & (42) 74 & $100( \pm 15)$ \\
\hline & & & - logical memory & (26) & $10( \pm 3)$ \\
\hline & & & - associated verbal pairs & (16) & $10( \pm 3)$ \\
\hline & & & Global Memory & (108) 86 & $100( \pm 15)$ \\
\hline & & & Delayed Recall & (74) 91 & $100( \pm 15)$ \\
\hline & & & $\begin{array}{l}\text { Language Boston Naming Test } \\
(/ 60)\end{array}$ & (53) & \\
\hline
\end{tabular}

FSIQ, full scale IQ; WAIS-IV, Wechsler Adult Intelligence Scale-IV; WMS-R, Wechsler Memory Scale; Stroop, Stroop task.

"Dutch/Flemish-like" accent. The patient's interview contained numerous contradictions (e.g., stating at first that she was a very lively, out-going person, but when asked later what she did during the day, she answered that she sat in a chair as all personal contact bored her and conversations with others-even friendswere too difficult and tiring). The description of her emotional and family life remained superficial and prosaic. The interview revealed increasing relational problems. The relationship with her husband left her "unaffected" and relationships with friends, family and relatives were unstable, marked by serious rows in which she responded unpredictably.

She confirmed egocentric and narcissistic tendencies. It was not possible to detect signs of perceptual aberration or other florid psychotic symptoms. A few weeks after the interview, a series of standardized psychodiagnostic tests were administered. Symptom validity and self-presentation tests, such as the List of Indiscriminate Psychopathology and the Supernormality Scale, did not yield indications for (conscious or unconscious) manipulation. Personality testing indicated a wide, undifferentiated personality disturbance. Interestingly, scores on both narcissism measures (NPI and PNI) were at most extreme upper ends, which is consistent with her answers during the clinical interview. A thymic disturbance and affective lability were objectified (APA, 2000; DSM-IV-TR, Axis I), but test results did not equivocally point toward a well-defined personality disturbance. Clinically, however, the patient gave clear indications of highly dependent, histrionic and borderline personality characteristics (APA, 2000; DSM-IV-TR, Axis II). On a psychodynamic structural level, she was considered to have a borderline personality organization level of functioning (Kernberg, 1984), because of an immature defensive functioning, intact reality testing, but severe lack of personality integration. This is relevant in relation to (interpersonal) acting out and poor bodily representation. The overall clinical presentation seemed chronic, pervasive and well established throughout her psychic development.

\section{Perceptual Analysis of Spontaneous Speech Sample}

A post-morbid speech sample was recorded in November 2013. It consisted of $5 \mathrm{~min}$ of video-recorded spontaneous speech, which was selected from an interview with the patient. In this interview she talks about her accent change and her relational and professional problems. This sample consisted of 644 words (including filled pauses). The patient also provided two (short) pre-morbid speech samples consisting of 43 and $26 \mathrm{~s}$ of conversational speech dating from April and July 2011, i.e., approximately half a year before the accident. When comparing pre- and post-morbid speech samples a number of striking differences were found. The first one was a very strong trilling aspect when realizing the uvular [R]. The trill is too excessive for French, and is more typical of the one in German and some regional variants of Dutch (36/644). According to Van de Velde and Van Hout, (1999, p. 178) "realizations of /r/ in standard Dutch until recently were the trilled realizations [R] and [r], with the uvular trill gaining in frequency and prestige especially in the Netherlands (Van Haeringen, 1924; Zwaardemaker and Eijkman, 1928; Blancquaert, 1934; Hol, 1951; Damsteegt, 1969; Mees and Collins, 1982; Vieregge and Broeders, 1993), but recently also in Flanders (Rogier, 1994).” For German this variant has been described as the most common allophone (Hall, 1993): the uvular trill-R constitutes a free (dialectal) variant of $/ \mathrm{r} /$, existing alongside the approximant /r/ (see Hall, 1993; Schiller, 1998). The excess trilling is particularly common in a prevocalic position (raconter, renverse, traite, ...: 27x), less 
frequent in intervocalic position (direct: $1 \mathrm{x}$ ) and postvocalic position (renverse, quart, ...:8x).

On the suprasegmental level, speech rate and articulation rate were particularly slow (speech rate: 2.67 syll/s, articulation rate: $3.813 \mathrm{syll} / \mathrm{s}$ ). Avanzi et al. (2012) found a mean speech rate of 4.7 syll/s (SD: 0.7$)$ and an articulation rate of 5.6 syll/s (SD: 0.6) for Belgian French of the Tournai region; the region our patient originated from. Melody and intonation appeared normal. In order to analyze rhythm, the Pairwise Variability Index was calculated (Low et al., 2001). Vocalic PVI amounted to 54.3. This is considerably higher than the accepted value for French (43.5), and is more in the range of the stress-timed languages, such as English (57.2), or German (59.7). However, the value is substantially lower than 65.5 , which is the reference value for Dutch (Grabe and Low, 2002). It is also worth mentioning that the patient did not realize any liaisons, a phenomenon by which a latent word-final consonant preceding a word starting with a vowel becomes audible. Our patient failed to realize this

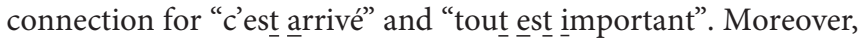
she did not realize the elision ${ }^{1}$ in "jentends" (pronounced as " $j e^{*}$ entends").

Grammar was perceived to be more simplistic than would be expected from a native-speaker of French. Sentences were perceived to be very short. At the morphosyntactic level the patient omitted the article "le" (1/644) as well as "de" in "là dedans," which was realized as "là dans" (2/644). In addition, the patient made six morphological errors against the definite article. In 5 instances, the patient used the masculine definite article instead of the female form (la même chose $\rightarrow$ le même chose; la tête $\rightarrow$ le tête; ma maison $\rightarrow$ mon maison; la pire chose $\rightarrow$ le pire chose; la chose $\rightarrow$ le chose).

\section{PERCEPTUAL ASSESSMENT OF THE FOREIGN ACCENT}

\section{Aims}

The foreign accent of the patient was assessed by a listening panel who listened to speech stimuli of the patient that were mixed with those of a native speaker of French and three nonnative speakers with a clear foreign accent. The listening panel was required to rate the degree of foreignness and they were asked to identify the mother tongue of each of the speakers. The ratings provide additional support for the diagnosis of FAS, whereas the accent attribution gives an indication of whether naive listeners are able to perceptually identify the mother tongue of native (including the FAS patient) and nonnative speakers of French. Furthermore, there was an interest to investigate whether there would be any differences between the FAS patient, the true non-native speakers and the native speaker of French.

\footnotetext{
${ }^{1}$ In English, the term elision is sometimes used as a synonym for deletion (e.g., Miller et al., 2006). For current article, we make a distinction between a "deletion" and an "elision" (French: "élision"), which is the "the suppression of a word-final vowel preceding a word starting with a vowel" (in spoken French this can refer to actual vowels, or the latent word-initial " $h$ " preceding a vowel-with a few exceptions; Schane and Filloux, 1967, p. 37, our translation).
}

\section{Methods}

\section{Materials and Samples}

Thirty students of French linguistics were recruited at the Université Libre de Bruxelles (ULB) in Brussels (age: 16-24, mean age: 20 years, 12 male and 18 female) and they were asked to rate the degree of "foreign-ness" of five speakers and to determine their native language. The students had no formal experience with speech and language pathology.

The stimuli for this experiment were taken from the intake interview, in which the patient explains what had happened to her (accident), and elaborates on her relational and professional problems. From this interview, 6 words, 3 phrases, and 6 sentences were chosen (see also: Dankovičová and Hunt, 2011). Care was taken that (a) the medical status of the FAS patient could not be derived from the stimuli and (b) the stimuli did not contain any morphological mistakes (as this could possibly influence the ratings of the listener panel). Stimulus selection was carried out by means of PRAAT, version 5.4 (PRAAT for Mac; Boersma and Weeninck, 2014).

\section{Speakers}

The speakers in this experiment were the FAS patient and four control speakers (Table 2) who were matched for gender with the FAS patient. The mean age of the controls was 35 years and 10 months, with an age range from 27 to 48 years old. Two speakers were Belgian but one was French-speaking and the other was Dutch-speaking (or "Flemish"; see also: Verhoeven, 2005). A third control subject spoke both Dutch and (American) English, as she was born in the USA, but moved to the Netherlands 1 year later. She was raised in English, but her education as of the age of 3 had been entirely in Dutch (100\% immersion; early bilingual; see also: Bhatia and Ritchie, 2013). She no longer had contact with relatives in the USA and lived alone in the Netherlands. She considered Dutch to be her dominant language. The fourth speaker was a Russian female. No attempt was made to match the accents to those that had been informally reported for the FAS patient. It was regarded likely that most listeners were familiar with the foreign accents of the control speakers. The control speakers read the 15 stimuli that had been selected from the speech of the FAS patient. The stimuli were recorded by means of a Marantz Professional PMD 661 portable recorder and manipulated for the purpose of this experiment via PRAAT (version 5.4, 2014).

\section{Stimuli and Assessment}

The perception experiment contained a total of 75 stimuli, i.e., 15 stimuli $\times 5$ speakers. Each presentation block consisted of one stimulus read by the five different speakers. The order of the speakers differed for each block (in pseudo-random order). The stimuli were separated by a $15 \mathrm{~s}$. pause to provide time for listeners to record their judgments. Total duration was $26 \mathrm{~min}$. $26 \mathrm{~s}$. The stimuli were played to the listeners in open field at their institution. The instructions to the test were given orally to the listening panel, but they were also able to read them. Raters provided demographic information (age, gender, country of origin, time in Belgium - if not born here, mother tongue, and other spoken languages including an indication of proficiency) 
TABLE 2 | Overview of the demographic characteristics of the FAS patient and the healthy, matched controls, including an indication of the level of French (CEFR, Common European Framework of Reference for Languages).

\begin{tabular}{|c|c|c|c|c|c|}
\hline Nature & Gender & Age & Country of birth & Mother tongue & Level in French (CEFR) \\
\hline FAS & $\mathrm{F}$ & 33 & Belgium & French & - \\
\hline Control 1 & $\mathrm{~F}$ & 36 & Belgium & French & - \\
\hline Control 2 & $\mathrm{~F}$ & 48 & Belgium & Dutch (Flemish) & B2 \\
\hline Control 3 & $\mathrm{~F}$ & 27 & United States of America* & English/Dutch (Netherlands) & B2 \\
\hline Control 4 & $\mathrm{~F}$ & 35 & Russia & Russian & $\mathrm{A} 2+/ \mathrm{B} 1$ \\
\hline
\end{tabular}

${ }^{*}$ Control 3 moved to the Netherlands one year after she was born. She was raised in English and learned Dutch as of the age of 3. Her education (immersion, $100 \%$; early bilingual) has been entirely in Dutch.

TABLE 3 | Overview of mean, median, standard deviations, minimum, maximum, range and interquartile range for the scores attributed to each speaker on a seven-point scale: 1, Definitely not a native speaker of French; 7, Definitely a native speaker of French.

\begin{tabular}{|c|c|c|c|c|c|c|c|}
\hline Speaker & Mean & Median & Standard deviation & Minimum & Maximum & Range & Interquartile range \\
\hline FAS & 3.791 & 4.000 & 2.318 & 1.000 & 7.000 & 6.000 & 5.000 \\
\hline French & 6.098 & 7.000 & 1.675 & 1.000 & 7.000 & 6.000 & 1.000 \\
\hline Dutch (Be) & 3.138 & 3.000 & 2.161 & 1.000 & 7.000 & 6.000 & 4.000 \\
\hline English/Dutch (NI) & 3.011 & 2.000 & 2.219 & 1.000 & 7.000 & 6.000 & 4.000 \\
\hline Russian & 1.407 & 1.000 & 0.913 & 1.000 & 7.000 & 6.000 & 0.000 \\
\hline
\end{tabular}

in a short questionnaire. For the experiment, they were asked to first rate the "foreign-ness" of the speaker on a scale from 1 to 7. This scale is to be interpreted as a continuum ranging from "definitely not a native speaker of French" $(=1)$ to "definitely a native speaker of French" $(=7)$. If their response was anything other than 7 , they were asked to indicate the mother tongue of the speaker (second part).

\section{Results}

\section{Statistical Analysis of the Accent Rating Experiment}

The data were processed statistically in SPSS version 22 (IBM Corp., 2013). First, inter-rater reliability was tested for each speaker by calculating the intraclass correlation coefficient (ICC). A two-way random model was chosen, as each item was assessed by each of the 30 raters and raters represented a randomly selected sample. Data were checked for agreement implying that systematic differences between raters were taken into account. For FAS: $\operatorname{ICC}_{(2,30)}=0.94$, French: $\operatorname{ICC}_{(2,30)}=0.903$, Dutch(Be): $\operatorname{ICC}_{(2,30)}=0.955$, English/Dutch(Nl): $\operatorname{ICC}_{(2,30)}=0.959$, and for Russian: $\operatorname{ICC}_{(2,30)}=0.523$.

Table 3 provides a summary of the descriptive statistics including means, standard deviations, minima and maxima, range as well as interquartile range for each of the five speakers. Based on the means $(\bar{x})$ as well as median (M) it is clear that the FAS speaker is situated roughly in the middle of the seven-point scale $(\bar{x}=3.791 ; \sigma=2.318$ and $M=4)$. The standard deviation was high, which indicates that the raters may have experienced some difficulty identifying the accent.

Application of the Kolmogorov-Smirnov test indicated that the data were not normally distributed (Kolmogorv-Smirnov: $p<0.1)$. Hence, non-parametric testing was applied. A Kruskall-Wallis $H$ test was carried out to test whether there was a significant difference between the scores attributed to the different speakers. Results for the Kruskall-Wallis $H$ test indicated that this was the case: $H_{(5)}=1393.60, p<0.0001$. However, additional Mann-Whitney $U$ tests (see Table 4) were carried out to identify the speakers who differed significantly from each other and who did not. All speaker differences were significant $(p<0.0001)$, except for one: Dutch $(\mathrm{Be})$ and English/Dutch(Nl) ( $p>0.003$ : Bonferroni correction; $p=0.290$ ).

A correspondence analysis was performed to get a two dimensional image of the strength (distance) of the associations between rating and speakers, based on frequency counts (Table 5: correspondence table; Figure 1). This showed that the associations between the native French speaker and rating " 7 " were particularly strong. The FAS speaker was situated more toward the higher ratings $(4,5,6,7)$ than, for instance, both native Dutch speakers and even markedly more so than the Russian speaker (strongly associated with rating " 1 "), who clearly occupied a more isolated position on the two-dimensional plot.

\section{Mother Tongue Identification}

It appeared that only $50 \%$ of the raters $(n=15 / 30)$ had indicated the mother tongue of each speaker for each stimulus. Nine raters were female, and six were male (age range: 16-23 years; mean age: 19 years). Figure 2 shows the different accents associated with the different speakers. Exact numbers can be found in Table 6 .

In general, the FAS patient was less often identified as "French" ( $n=61 / 225 ; 27.1 \%)$ than as a speaker of other languages $(72.9 \%)$. However, the other languages attributed to the FAS patient were most often Romance languages (Spanish: $n=21$; Italian: $n=$ 21; Portuguese: $n=5$; Romanian: $n=4 ; n=112 / 225 ; 49.8 \%)$. Still, she was identified as Dutch in $21.3 \%$ of the stimuli ( $n=$ $48 / 225)$, and as German in $4 \%$ of stimuli $(n=10 / 225)$. The 
TABLE 4 | Overview of the inter-speaker comparisons (Mann-Whitney $U$-tests).

\begin{tabular}{|c|c|c|c|c|c|c|c|}
\hline Speaker comparison & N stimuli & Mean ranks & Sum of mean ranks & Mann Whitney U & Wilcoxon W & $\boldsymbol{Z}$ & $p$ \\
\hline FAS & 450 & 322.88 & 145294.50 & 43819.500 & 145294.500 & -15.497 & 0.000 \\
\hline French & 450 & 578.12 & 260155.50 & & & & \\
\hline FAS & 450 & 487.20 & 219240.00 & 84735.00 & 186210.00 & -4.326 & 0.000 \\
\hline Dutch(Be) & 450 & 413.80 & 186210.00 & & & & \\
\hline FAS & 450 & 494.07 & 222331.50 & 81643.500 & 183118.500 & -5.154 & 0.000 \\
\hline English/Dutch(NI) & 450 & 406.93 & 183118.50 & & & & \\
\hline FAS & 450 & 587.61 & 264424.50 & 39550.500 & 141025.500 & -17.102 & 0.000 \\
\hline Russian & 450 & 313.39 & 141025.50 & & & & \\
\hline French & 450 & 606.39 & 272845.00 & 31100.00 & 132575.000 & -18.728 & 0.000 \\
\hline Dutch(Be) & 450 & 294.61 & 132575.00 & & & & \\
\hline French & 450 & 604.38 & 271972.00 & 32003.000 & 133478.000 & -18.576 & 0.000 \\
\hline English/Dutch(NI) & 450 & 296.62 & 133478.00 & & & & \\
\hline French & 450 & 659.11 & 296598.00 & 7377.000 & 108852.000 & -25.523 & 0.000 \\
\hline Russian & 450 & 241.89 & 108852.00 & & & & \\
\hline Dutch(Be) & 450 & 459.37 & 206717.50 & 97257.500 & 198732.500 & -1.059 & 0.290 \\
\hline English/Dutch(NI) & 450 & 441.63 & 198732.50 & & & & \\
\hline Dutch(Be) & 450 & 558.65 & 251391.50 & 52583.5 & 154058.500 & -13.864 & 0.000 \\
\hline Russian & 450 & 342.35 & 154058.50 & & & & \\
\hline English/Dutch(NI) & 450 & 547.76 & 246494.00 & 57481.000 & 158956.00 & -12.628 & 0.000 \\
\hline Russian & 450 & 353.24 & 158956.00 & & & & \\
\hline
\end{tabular}

TABLE 5 | Correspondence table with frequency data for the different speakers.

\begin{tabular}{|c|c|c|c|c|c|c|c|c|}
\hline \multicolumn{9}{|c|}{ Correspondence table } \\
\hline \multirow[t]{2}{*}{ Speaker } & \multicolumn{8}{|c|}{ Rating } \\
\hline & 1 & 2 & 3 & 4 & 5 & 6 & 7 & Active margin \\
\hline FAS & 118 & 62 & 40 & 42 & 45 & 50 & 93 & 450 \\
\hline French & 18 & 15 & 21 & 10 & 34 & 41 & 311 & 450 \\
\hline Dutch(BE) & 165 & 59 & 51 & 38 & 51 & 33 & 53 & 450 \\
\hline English/Dutch(NL) & 183 & 62 & 47 & 35 & 36 & 22 & 65 & 450 \\
\hline Russian & 349 & 53 & 27 & 11 & 8 & 1 & 1 & 450 \\
\hline Active margin & 833 & 251 & 186 & 136 & 174 & 147 & 523 & 2250 \\
\hline
\end{tabular}

1, Definitely not a native speaker of French; 7, Definitely a native speaker of French.

FAS patient was less often identified as "French" than the native French speaker $(n=214 / 225 ; 95.1 \%)$, which corroborates the findings for the first part of the study. Hence, there seemed to be a clear difference in the perception of the FAS patient and the nonimpaired French control speaker. The Dutch (Be) speaker was associated with "Dutch" in 53.3\% $(n=120 / 225)$ of the stimuli, whereas for the English/Dutch(Nl) speaker this was $28 \%$ of the stimuli $(n=63 / 225)$. In $8 \%$ of the stimuli she was associated with "English" ( $n=19 / 225)$. The Russian speaker was correctly associated with her native language in $28.4 \%(n=64 / 225)$ of the stimuli.

Interestingly, the accent stratification was most diverse for the FAS patient (16 different mother tongues were associated with her stimuli). For the other speakers, the number of attributed accents was: English/Dutch(Nl): 15; Russian: 13; Dutch (Be): 12; and French: 5. Equally interesting to note is that the accent of the FAS patient could not be identified in 30 items: this is considerably more often than for the other control speakers: French: 2; Dutch (Be): 14; English/Dutch (Nl): 16; Russian: 1.

\section{DISCUSSION}

This article discusses the case of a patient who developed FAS in the absence of demonstrable damage to the central nervous system. No structural damage was visible on repeat CT and MRI of the brain. Repeat neurological and neurophysiological examinations were normal. An in-depth psychodiagnostic workup was carried out (a) to confirm the existence of psychological issues and (b) to identify a possible psychiatric disorder. Unfortunately, testing did not reveal a clearly delineated disorder on either axis I or II of the DSM-IV-TR (APA, 2000). Test results were, however, indicative of a highly dependent, hysterical and borderline personality. Although psychological problems were considered persistent and chronic, 
there were several elements in the clinical interviews that could corroborate the hypothesis of a psychogenic origin of the accent change.

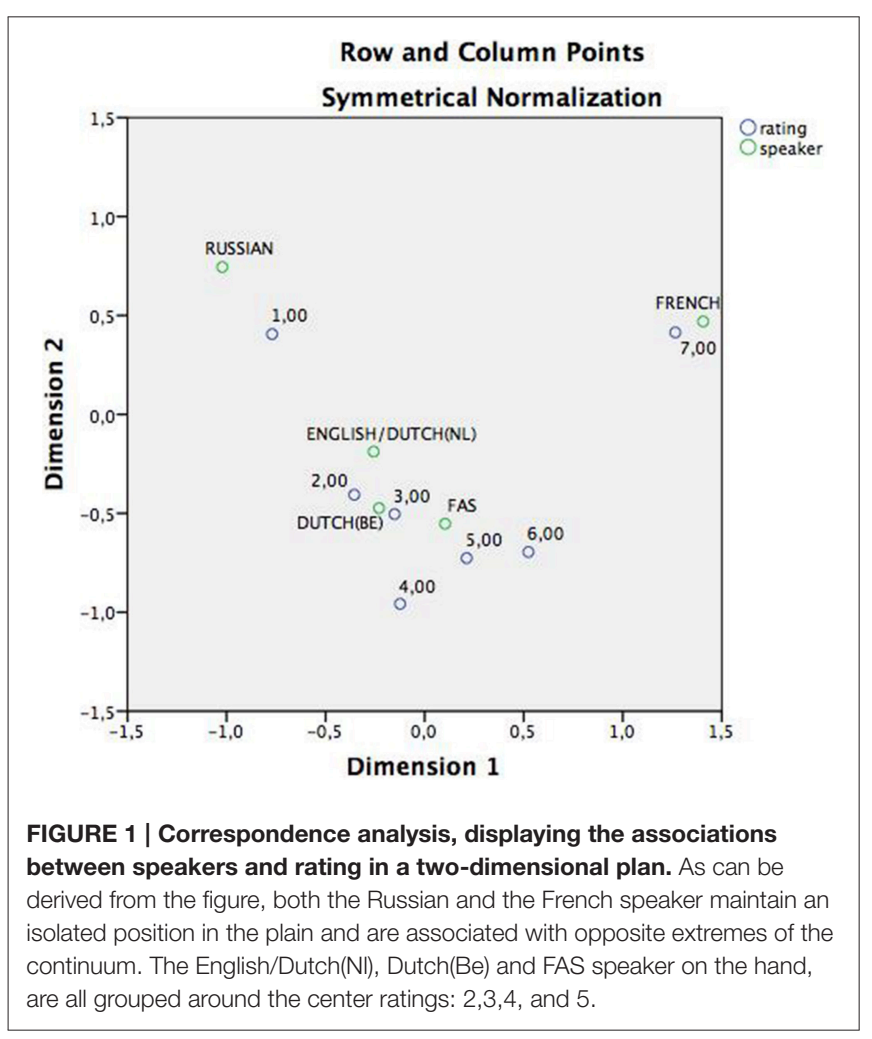

First, the accent diminished whenever there was a psychological breakthrough during the clinical interview (Avbersek and Sisodiya, 2010; see also: Keulen et al., 2016²). More specifically these episodes occurred when the patient talked about her relational problems, issues at her former workplace and the fact that she no longer had a job at the moment the interview took place. Interestingly, the negative impact of emotional disequilibrium, feelings of stress and/or anxiety on the recovery process has previously been established for neurological speech and language disorders (see also: Cahana-Amitay and Albert, 2015). In contrast, current patient seemed to benefit from these emotional triggers.

Second, there was a correspondence between the culmination of disputes with her line manager, which ultimately led her dismissal, and the onset of the accent: both occurred approximately 6 months after the accident.

Third-and related to prior argument-the increased emotional lability and hysteric symptoms may have been reinforced by the adverse life events that had marked her life in rapid succession: the car accident, the accent shift, the dismissal, and the relational problems. According to Avison and Turner (1988) the relationship between adverse life events and psychological distress is often underestimated. According to Charles et al. (2013) even naturally occurring daily stressors or minor affective experiences can have a far-reaching impact on mental health (p. 739). It is important to note that at the time we saw the patient, she had been unemployed for about a year and a half and had marital problems.

${ }^{2}$ In this recently published article, another case of psychogenic FAS is presented. The patient suddenly lost her accent during a temper tantrum.

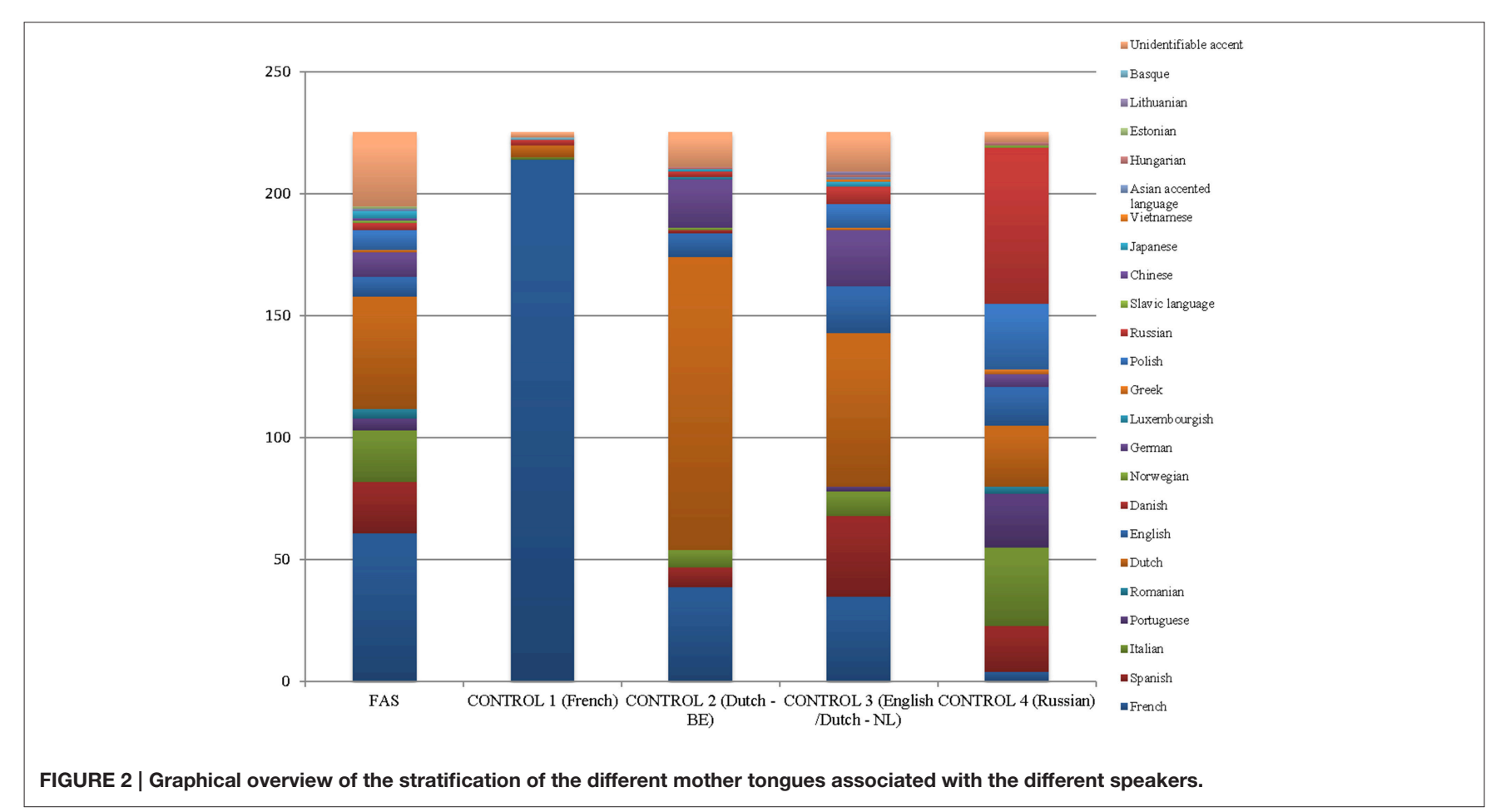


TABLE 6 | Overview of the mother tongues (rows) associated with each of the speakers (columns).

\begin{tabular}{|c|c|c|c|c|c|}
\hline & FAS & French & Dutch & English/Dutch & Russian \\
\hline French & 61 & 214 & 39 & 35 & 4 \\
\hline Spanish & 21 & 0 & 8 & 33 & 19 \\
\hline Italian & 21 & 1 & 7 & 10 & 32 \\
\hline Portuguese & 5 & 0 & 0 & 2 & 22 \\
\hline Romanian & 4 & 0 & 0 & 0 & 3 \\
\hline Dutch & 46 & 5 & 120 & 63 & 25 \\
\hline English & 8 & 0 & 10 & 19 & 16 \\
\hline Danish & 0 & 0 & 1 & 0 & 0 \\
\hline Norwegian & 0 & 0 & 1 & 0 & 0 \\
\hline German & 10 & 0 & 20 & 23 & 5 \\
\hline Luxembourgish & 0 & 0 & 1 & 0 & 0 \\
\hline Greek & 1 & 0 & 0 & 1 & 2 \\
\hline Polish & 8 & 0 & 0 & 10 & 27 \\
\hline Russian & 3 & 2 & 2 & 7 & 64 \\
\hline Slavic & 1 & 0 & 0 & 0 & 1 \\
\hline Chinese & 1 & 0 & 0 & 0 & 0 \\
\hline Japanese & 3 & 0 & 1 & 2 & 0 \\
\hline Vietnamese & 0 & 0 & 0 & 1 & 0 \\
\hline Asian-sounding accent & 1 & 0 & 0 & 1 & 0 \\
\hline Hungarian & 0 & 0 & 1 & 1 & 1 \\
\hline Estonian & 1 & 0 & 0 & 0 & 0 \\
\hline Lithuanian & 0 & 0 & 0 & 1 & 0 \\
\hline Turkish & 0 & 0 & 0 & 0 & 0 \\
\hline Basque & 0 & 1 & 0 & 0 & 0 \\
\hline Unidentifiable & 30 & 2 & 14 & 16 & 4 \\
\hline TOTAL & 225 & 225 & 225 & 225 & 225 \\
\hline
\end{tabular}

Languages pertaining to the same language family have been grouped together.

The patient had repeatedly complained about (sustained) attentional and amnestic problems, as well as slow cognitive processing. These complaints were confirmed by neuropsychological test results: the patient demonstrated impaired processing on the cognitive tasks appealing to working memory, attention, and executive function. These complaints have been noted regularly in psychogenic FAS patients (Poulin et al., 2007; Cottingham and Boone, 2010; Jones et al., 2011; case Roy et al., 2012) and have more generally been associated with somatic disorders (Niemi et al., 2002; Trivedi, 2006; Demir et al., 2013). However, studies claiming such an association have been the subject of scientific scrutiny, because hardly anyone administered symptom validity tests to their participants prior to inclusion. Delis and Wetter (2007) suggest that patients with psychogenic disorders may exaggerate cognitive deficits, due to external (medico-legal reasons, treatment), internal/interpersonal incentives (in order to sustain a dependent relationship with specialist or other) or even for unspecified reasons ("not otherwise specified"). The current patient completed symptom validity tests, which turned out negative for malingering and feigning. Moreover, neurocognitive testing was carried out on two occasions (2 years apart, both post-morbid). This is crucial, as significant underperformance or inconsistencies in cognitive test scores or profiles across repeated evaluation would be considered indicative of a feigned cognitive deficit.

In the case of our patient the profile seems mostly consistent with a post-concussion cognitive syndrome after a minor head trauma. The objectively attested cognitive deficits and the negligence of the cognitive complaints after prior examinations might also have contributed to the development of the FAS.

On a linguistic level, the patient's speech was characterized by the realization of the uvular $\mathrm{R}$ with a marked, atypical trill and occasionally, she deleted phonemes. Furthermore, the patient spoke at a very slow speech rate and had a speech rhythm that was qualified as stress-timed, whilst French is a syllable-timed language (Grabe and Low, 2002). The segmental and suprasegmental characteristics noted for this patient do not seem to be restricted to a psychogenic population: all have been attested for neurogenic FAS patients as well. However, the isolated, morphological deficits, which irregularly affected articles, and the occasional pronunciation deficits affecting liaisons and elisions (phenomena typifying French) seemed incredible. The grammatical deficit is very different and less substantial than the agrammatism and paragrammatism encountered in aphasics, for instance. Some degree of conscious or subconscious manipulation cannot be ruled out. Incredible grammatical disorders of the like have previously been reported in other psychogenic cases (e.g., Van Borsel et al., 2005; Cottingham and Boone, 2010).

Some speech characteristics might have been consistent with the impression of a Dutch or German accent. However, results of the listening experiment suggest that the patient was perceptually situated midway between a true non-native speaker of French and a native speaker of French. This finding is in line with what has been found in the experiments of Di Dio et al. (2006), Kanjee et al. (2010) and Verhoeven et al. (2013). However, the methodology in Verhoeven et al. (2013) and Kanjee et al. (2010) differed from the current one in the sense that they did not select words and sentences in pseudo-random order, but provided raters with spontaneous speech samples (Verhoeven et al., 2013) or elicited (read) sentences (Kanjee et al., 2010). For Di Dio et al. (2006) it is not clear what type of stimuli was used. The methodology in the present experiment was more comparable to the approach of Dankovičová and Hunt (2011), who used single words and phrases. As far the identification of the linguistic background of the speakers is concerned, it was found that the FAS patient was associated with French in only $27.1 \%$ of the stimuli. The French-speaking control subject on the other hand was almost always recognized as French (95.1\%). The patient also demonstrated the most diverse association patterns regarding her native language. The "uncertainty" expressed in the first part of the experiment $(M=$ 4) compares well with the second part of the study: the patient was associated with 16 different possible native languages, and for $13 \%$ of the items, the mother tongue could not be identified. Furthermore, the hypothesis that the patient was perceived as Dutch or German was not entirely confirmed, as most listeners still perceived her as being a native speaker of a Romance language (for $49.8 \%$ of the stimuli, including French, Italian, Spanish, Portuguese, and Romanian; in comparison: Germanic 
languages, including English, Dutch and German: 28.4\% of the stimuli).

Remarkably, the patient did not seem bothered by the accent change at all. Nevertheless, there were clear problems at the cognitive-behavioral and psychological level (mentioned above). Moreover, she was not keen to be treated for the condition. Rather, she wanted to show off with it. She did not seem to be overtly concerned about her symptoms. This is unlike what is mostly seen in neurogenic patients, who are emotionally and psychologically affected by FAS (Miller et al., 2011). In fact, to the best of our knowledge, there are only two other reports (Laures-Gore et al., 2006; Tailby et al., 2013) in which it was mentioned that patients were almost completely indifferent to the negative implications. These cases were classified as "mixed FAS" by Verhoeven and Mariën (2010): these patients further optimize their accent and often start to use words of the language, which is suggested by their accent in order to create a more authentic personality. The use of foreign-sounding words or a more formal language variant has also been noted for psychogenic FAS patients (Reeves and Norton, 2001; Poulin et al., 2007; see also: Reeves et al., 2007, case 3; Polak et al., 2013). The processes which invoke this kind of change in language use, still remain to be clarified. For neurogenic cases, some positive associations have also been noted. According to some patients, living with FAS opened new horizons. However, in the longer term, the negative perceptions from others, the hybrid identity, a loss of sense of belonging, a breakdown of relationships, and the incapacity of medical staff to explain the change all lead to frustrations (Miller et al., 2011).

Patient coping strategies, psycho-emotional and -social implications have generally been underreported in the literature about both psychogenic and neurogenic FAS (for neurogenic patients: Munson, 2005; Miller et al., 2006, 2011; Moreno-Torres et al., 2013). Future research should identify and study the effects

\section{REFERENCES}

Abel, T., Hebb, A. O., and Silbergeld, D. L. (2009). Cortical stimulation mapping in a patient with foreign accent syndrome: a case report. Clin. Neurol. Neurosurg. 111, 97-101. doi: 10.1016/j.clineuro.2008. 07.014

American Psychiatric Association (2000). Diagnostic and Statistical Manual of Mental Disorders: DSM-IV-TR. Washington, DC: American Psychiatric Association.

Avanzi, M., Orbin, N., Bordal, G., and Bardiaux, A. (2012). La variation prosodique dialectale en fraçais. Données et hypothèses. Actes de la conférence conjointe. Jep Taln Recital 1, 457-464.

Avbersek, A., and Sisodiya, S. (2010). Does the primary literature provide support for clinical signs used to distinguish psychogenic nonepileptic seizures from epileptic seizures? J. Neurol. Neurosur. Ps. 81, 719-725. doi: 10.1136/jnnp.2009.197996

Avison, W., and Turner, R. J. (1988). Stressful life events and depressive symptoms: disaggregating the effects of acute stressors and chronic stains. J. Health Soc. Behav. 29, 253-264. doi: 10.2307/2137036

Bakker, J. I., Appeldoorn, S., and Metz, L. M. (2004). Foreign accent syndrome in a patient with multiple sclerosis. Can. J. Neurol. Sci. 31, 271-272. doi: $10.1017 /$ S0317167100053956

Baumgartner, J., and Duffy, J. R. (1997). Psychogenic stuttering in adults with and without neurologic disease. J. Med. Speech-Lang. Path. 5, 75-95. of this syndrome at the personal and inter-personal level to allow for a full rehabilitation of both speech profile and psychological well-being.

\section{CONCLUDING REMARKS}

Only a handful of putative psychogenic FAS cases have been described in the literature and many researchers have been hesitant to conclude to an underlying psychogenic etiology. Although it is hard to provide evidence for a direct causal link between the psychological factor in play and FAS, ample evidence exists that the FAS symptoms (and their course) in this patient are of a psychogenic nature: (1) clear absence of (visible) neurological damage or clinical evidence for a neurological disorder, in conjunction with (2) the presence of psychological and psychiatric factors, (3) the timing of the onset of the accent change, (4) the atypical and fluctuating symptom course, (5) irregular and incredible morphological mistakes occurring in a short sample of spontaneous speech, and the fact that (6) the patient was unconcerned by the change of accent. As most of the psychogenic FAS cases were published in the last decades, reports of cognitive-behavioral deficits such as the ones displayed by current patient are becoming increasingly important with a view to the development of the proper therapeutic approaches for this psychogenic FAS population.

\section{AUTHOR CONTRIBUTIONS}

Acquisition of data: SK, LDP, and PM. Analysis and interpretation of data: SK, JV, RJ, LDP, RB, and PM. Drafting the manuscript: SK and PM. Critical manuscript revision: all authors. Critical revision of reviewed manuscript: SK, JV, and PM. Final manuscript approval: SK and PM on behalf of all authors.

Baumgartner, J. M. (1999). “Acquired psychogenic stuttering”, in Acquired Psychogenic Stuttering, 2nd Edn., ed R. Curlee (New York, NY: Thieme Medical Publishers), 269-288.

Blancquaert, E. (1934). Practische Uitspraakleer van de Nederlandsche Taal. Antwerpen: De Sikkel.

Beck, A. T., Steer, R. A., and Brown, G. K. (1996). Manual for the Beck Depression Inventory-II. San Antonio, TX: Psychological Corporation.

Bhatia, T. K., and Ritchie, W. C. (2013). The Handbook of Bilingualism, 2 nd Edn. Oxford: Wiley Interscience, Blackwell Publ.

Boersma, P., and Weeninck, D. (2014). Praat: Praat: Doing Phonetics by Computer [Computer program]. Version 5.4. Available online at: http://www.praat.org/

Brickenkamp, D., and Zillmer, E. A. (1998). d2 Test of Attention. Göttingen: Hogrefe \& Huber.

Butcher, J. N., Dahlstrom, W. G., Graham, J. R., Tellegen, A. M., and Kaemmer, B. (1989). Minnesota Multiphasic Personality Inventory-2 (MMPI-2): Manual for administration and scoring. Minneapolis, MN: University of Minnesota Press.

Cahana-Amitay, D., and Albert, M. L. (2015). Redefining Recovery from Aphasia. New York, NY: Oxford University Press.

Chanson, J. B., Kremer, S., Blanc, F., Marescaux, C., Namer, I. J., and de Seze, J. (2009). Foreign accent syndrome as a first sign of multiple sclerosis. Mult. Scler. 15, 1123-1125. doi: 10.1177/1352458509106611

Charles, S. T., Piazza, J. R.; Mogle, J., Sliwinski, M. J., and Almeida, D. M. (2013). The wear and tear of daily stressors on mental health. Psychol. Sci. 24, 733-741. doi: $10.1177 / 0956797612462222$ 
Cima, M., Merckelbach, H., Hollnack, S., Butt, C., Kremer, K., Schellbach-Matties, R., et al. (2003). The other side of malingering: supernormality. Clin. Neuropsychol. 17, 235-243. doi: 10.1076/clin.17.2.235. 16507

Cottingham, M. E., and Boone, K. B. (2010). Non-credible language deficits following mild traumatic brain injury. Clin. Neuropsychol. 24, 1006-1025. doi: 10.1080/13854046.2010.481636

Critchley, M. (1962). "Regional “accent”, Demotic Speech, and Aphasia," in Livre Jubilaire Docteur Ludo Van Bogaert (Bruxelles: Les Editions Acta Medica Belgica), 182-191.

Damsteegt, B. C. (1969). Over Relevante Kenmerken van Fonemen en de Nederlandse R. Leiden: Universitaire Pers.

Dankovičová, J., and Hunt, C. (2011). Perception of foreign accent syndrome speech and its relation to segmental characteristics. Clin. Ling. Phonet. 25, 85-120. doi: 10.3109/02699206.2010.513027

Demir, S., Çelıkel, F. Ç., Taycan, S. E., and Etıkan, İ. (2013). Konversiyon Bozukluğunda Nöropsikolojik Değerlendirme [Neuropsychological assessment in conversion disorder]. Turk Psikiyatri Derg. 24, 75-83.

Delis, D. C., Kaplan, E., and Ober, B. A. (2000). California Verbal Learning Test, 2nd Edition. San Antonio, TX: Psychological Corporation.

Delis, D. C., and Wetter, S. (2007). Cogniform disorder and cogniform condition: proposed diagnoses for excessive cognitive symptoms. Arch. Clin. Neuropsych. 22, 589-604. doi: 10.1016/j.acn.2007.04.001

Di Dio, C., Schulz, J., and Gurd, J. M. (2006). Foreign accent syndrome: in the ear of the beholder? Aphasiology 20, 951-962. doi: 10.1080/02687030600739356

Diguer, L., Turmel, V., Da Silva, L., Mathieu, V., Marcoux, L. A., and Lapointe, T. (2014). EPA-0614-Development and initial structure analysis of a french version of the pathological narcissism inventory. Eur. Psychiat. 29:1. doi: $10.1016 /$ s0924-9338(14)77997-0

Grabe, E., and Low, E. L. (2002). "Acoustic correlates of rhythm class," in Papers in Laboratory 465 Phonology 7, eds C. Gussenhoven and N. Warner (Berlin: De Gruyter Mouton), 515-546.

Grant, D. A., and Berg, E. (1948). A behavioral analysis of degree of reinforcement and ease of shifting to new responses in Weigl-type card-sorting problem. J. Exp. Psych. 38, 404-411. doi: 10.1037/h0059831

Gurd, J. M., Coleman, J. S., Costello, A., and Marshall, J. C. (2001). Organic or functional? A new case of foreign accent syndrome. Organic of functional? A new case of foreign accent syndrome. Cortex 37, 715-718. doi: 10.1016/s00109452(08)70622-1

Haley, K., L., Roth, H., Helm-Estabrooks, N., and Thiessen, A. (2010). Foreign accent syndrome due to conversion disorder: phonetic analyses and clinical course, J. Neurolinguist. 23, 1-16. doi: 10.1016/j.jneuroling.2009.08.001

Hall, T. A. (1993). The phonology of German /R/*. Phonology 10, 83-105. doi: $10.1017 /$ S0952675700001743

Hol, A. R. (1951). Enkele Opmerkingen Over de Uitspraak van de R. Alphen aan den Rijn: N. Samsom.

IBM Corp. (2013). IBM SPSS Statistics for Mac OSX, Version 22.0. Armonk, NY: IBM Corp.

Jones, H., N., Story, T., J., Collins, T. A., DeJoy, D., et al. (2011). Multidisciplinary assessment and diagnosis of conversion disorder in a patient with foreign accent syndrome. Behav. Neurol. 24, 245-255. doi: 10.1155/2011/786560

Kanjee, R., Watter, S., Sévigny, A., and Humphreys, K. R. (2010). A case of foreign accent syndrome: Acoustic analyses and an empirical test of accent perception. J. Neurolinguistics. 23, 580-598. doi: 10.1016/j.jneuroling.2010.05.003

Kaplan, E., Goodglass, H., and Weintraub, S. (1983). Boston Naming Test. Philidelphia, MA: Lea \& Febiger.

Kernberg, O. F. (1984). Severe Personality Disorders: Psychotherapeutic Strategies. New Haven, CT: Yale University Press.

Keulen, S., Verhoeven, J., Bastiaanse, R., Mariën, P., Jonkers, R., Mavroudakis, N., et al. (2016). Perceptual accent rating and attribution in psychogenic FAS: some further evidence challenging whitaker's operational definition. Front. Hum. Neurosci. 10:62. doi: 10.3389/fnhum.2016.00062

Laures-Gore, J., Contado Henson, J., Weismer, G., and Rambow, M. (2006). Two cases of foreign accent syndrome: an acoustic-phonetic description. Clin. Linguist. Phonet. 20, 781-790. doi: 10.1080/02699200500391105

Lewis, S., Ball, L. J., and Kitten, S. (2013). Acoustic and perceptual correlates of foreign accent syndrome with manic etiology; a case study. Commun. Disord. Q. 34, 242-248. doi: 10.1177/1525740112466913
Low, E. L., Grabe, E., and Nolan, F. (2001). Quantitative characterizations of speech rhythm: 511 syllable-timing in Singapore English. Lang. Speech 43, 377-401.

Masao, R., Martinez, A., Cisneros, J., and Alonso, M. (2011). Síndrome de acento extranjero. Arch. Neurocien. (Mex). 16, 167-169.

Mees, I., and Collins, B. (1982). A phonetic description of the consonant system of standard dutch (ABN). J. Intern. Phonetic Associat. 12, 2-12. doi: 10.1017/S0025100300002358

Merckelbach, H., Jelici, M., and van Impelen, A. (2013). De structured inventory of malingered symptomatology (sims ): een update. Tijdschrift voor Neuropsychologie 8, 170-178.

Merten, T., and Stevens, A. (2012). List of Indiscriminate Psychopathology (LIPP). Berlin: Unpublished Manuscript.

Miller, N., Lowit, A., and O'Sullivan, H. (2006). What makes acquired foreign accent syndrome foreign. J. Neurolinguist. 19, 385-409. doi: 10.1016/j.jneuroling.2006.03.005

Miller, E., Taylor, J., Howe, C., and Read, J. (2011). Living with foreign accent syndrome: Insider perspectives. Aphasiology 25, 1053-1068. doi: 10.1080/02687038.2011.573857

Moreno-Torres, I., Berthier, M. L., del Mar Cid, M., Green, C., Gútierrez, A., García-Casares, N., et al. (2013). Foreign accent syndrome: a multimodal evalation in the search of neuroscience-driven treatments. Neuropsychologia 51, 520-537. doi: 10.1016/j.neuropsychologia.2012.11.010

Munson, P. D. (2005). Foreign accent syndrome: anatomic, pathophysiological and psychosocial considerations. South Dakota J. Med. 58, 187-189.

Niemi, P. M., Portin, R., Aalto, S., Hakala, M., and Karlson, H. (2002). Cognitive functioning in severe somatization-a pilot study. Acta Psychiatr. Scand. 106, 461-463. doi: 10.1034/j.1600-0447.2002.01445.x

Paquier, C., and Assal, F. (2007). A case of oral spelling behavior: another environmental dependency syndrome. Cogn. Behav. Neurol. 20, 235-237. doi: 10.1097/WNN.0b013e31814da110

Pincus, A. L., Ansell, E. B., Pimentel, C. A., Cain, N. M., Wright, A. G., and Levy, K. N. (2009). Initial construction and validation of the pathological narcissism inventory. Psychol. Assessment 21, 365-379. doi: 10.1037/a0016530

Polak, A. R., Witteveen, A. B., Mantione, M., Figee, M., de Koning, P., Olff, M., et al. (2013). Deep brain stimulation for obsessive-compulsive disorder affects language: a case report. Neurosurgery 73, 907-910. doi: 10.1227/NEU.0000000000000022

Poulin, S., Macoir, J., Paquet, N., Fossard, M., and Gagnon, L. (2007). Psychogenic or neurogenic origin of agrammatism and foreign accent syndrome in a bipolar patient: a case report. Ann. Gen. Psychiatry 6:1. doi: 10.1186/1744-859X-6-1

Raskin, R., and Hall, C. S. (1979). A narcissistic personality inventory. Psychol. Rep. 45:590. doi: 10.2466/pr0.1979.45.2.590

Reeves, R. R., and Norton, J. W. (2001). Foreign accent-like syndrome during psychotic exacerbations. Neuropsy. Neuropsy. Be. 14, 135-138.

Reeves, R. R., Burke, R. S., and Parker, J. D. (2007). Characteristics of psychotic patients with Foreign Accent Syndrome. J. Neuropsych. Clin. Neurosci. 19, 70-76. doi: 10.1176/jnp.2007.19.1.70

Reitan, R. (1958). Validity of the Trail Making test as an indicator of organic brain damage. Percept. Motor Skill. 8, 271-276. doi: 10.2466/PMS.8.7.271-276

Rogier, D. (1994). De Verspreiding van een hooggewaardeerd taalkenmerk: de Huig-R rond gent. Taal en Tongval Themanummer 7, 43-53.

Roth, C. E., Aronson, A. E., and Davis, L. J. (1989). Clinical studies in psychogenic stuttering of adult onset. J. Speech Hear. Disord. 54, 634-646. doi: 10.1044/jshd.5404.634

Rotter, J. B., Lah, M. I., and Rafferty, J. E. (1992). The Rotter Incomplete Sentences Blank, 2nd Edn. New York, NY: Psychological Corporation.

Roy, J.-P., Macoir, J., Martel-Sauvage, V., and Boudreault, C.-A. (2012). Two French-speaking cases of foreign accent syndrome: an acoustic-phonetic analysis. Clin. Linguist. Phonet. 26, 934-945. doi: 10.3109/02699206.2012.723237

Schane, S. A., and Filloux, O. (1967). L'élision et la liaison en Français, Langages 8, 37-59. doi: 10.3406/lgge.1967.2891

Schiller, N. O. (1998). "The Phonetic Variation of German /r/," in Variation und Stabilität in der Wortstruktur. Untersuchungen zu Entwicklung, Erwerb und Varietäten des Deutschen und anderer Sprachen, eds M. Butt and N. Fuhrhop (Olms: Hildesheim), 261-287.

Stroop, J. (1935). Studies of interference in serial verbal reaction. J. Exp. Psych. 18, 643-662. doi: 10.1037/h0054651 
Tailby, C., Fankhauser, J., Josev, E. K., Saling, M. M., and Jackson, G. D. (2013). Clinical foreign accent syndrome evolving into a multiplicity of accents. J. Neurolinguist. 26, 348-362. doi: 10.1016/j.jneuroling.2012. 11.002

Thygesen, K. L., Drapeau, M., Trijsburg, R. W., Lecours, S., and de Roten, Y. (2008). Assessing defense styles: factor structure and psychometric properties of the new Defense Style Questionnaire 60 (DSQ-60). Intern. J. Psychol. Psychol. Ther. 8, 171-181.

Tippett, D. C., and Siebens, A. A. (1991). Distinguishing psychogenic form neurogenic dysfluency when neurologic and psychologic factors coexist. $J$. Fluency Disord. 16, 3-12. doi: 10.1016/0094-730X(91)90031-7

Tomasino, B., Marin, D., Maieron, M., Ius, T., Budai, R., Fabbro, F., et al. (2013). Foreign accent syndrome: a multimodal mapping study. Cortex 49, 18-39. doi: 10.1016/j.cortex.2011.10.007

Trivedi, J. K. (2006). Cognitive deficits in psychiatric disorders: current status. Indian J. Psychiatry 48, 10-20. doi: 10.4103/0019-5545.31613

Tsuruga, K., Kobayashi, T., Hirai, N., and Koto, S. (2008). Foreign accent syndrome in a case of dissociative (conversion) disorder. Seishin Shinkeigaku Zasshi 110, 79-87.

Van Borsel, J., Janssens, L., and Santens, P. (2005). Foreign Accent syndrome: an organic disorder? J. Commun. Disord. 38, 421-429. doi: 10.1016/j.jcomdis.2005.03.004

Van de Velde, H., and Van Hout, R. (1999). "The pronunciation of (r)," in Linguistics in the Netherlands, eds R. van Bezooijen and R. Kager (Amsterdam, NL: John Benjamins), 177-188.

Van Haeringen, C. B. (1924). Eenheid en Nuance in Beschaafd-Nederlandse Uitspraak. Nieuwe Taalgids 18, 65-85.

Verhoeven, J. (2005). Belgian standard dutch. J. Intern. Phonet. Associat. 35, 243-247. doi: 10.1017/S0025100305002173

Verhoeven, J., Mariën, P., Engelborghs, S., D’Haenen, H., and De Deyn, P. P. (2005). A foreign speech accent in a case of conversion disorder. Behav. Neurol. 16, 225-232. doi: 10.1155/2005/989602

Verhoeven, J., and Mariën, P. (2010). Neurogenic foreign accent syndrome: articulatory setting, segments and prosody in a Dutch speaker. J. Neurolinguist. 23, 599-614. doi: 10.1016/j.jneuroling.2010.05.004
Verhoeven, J., De Pauw, G., Pettinato, M., Hirson, A., Van Borsel, J., and Mariën, P. (2013). Accent attribution in speakers with Foreign Accent Syndrome. J. Commun. Disord. 46, 156-168. doi: 10.1016/j.jcomdis.2013.02.001

Vieregge, W. H., and Broeders, A. P. A. (1993). Intra- and interspeaker variation of /r/ in Dutch. Proc. Euro. 93, 267-270.

Villaverde-Gonzalález, R., Fernández-Villalba, E., Moreno-Excribano, A., AliásLinares, E., and García-Santos, J. M. (2003). Síndrome del acento extanjero como primera manifestaión de esclerosis múltiple. Rev. Neurol. 26, 1035-1039.

Wechsler, D. (1987). WMS-R: Wechsler Memory Scale-Revised: Manual. San Diego, CA: Harcourt.

Wechsler, D. (2011). Echelle D'Intelligence de Wechsler Pour Adultes. Paris: Pearson/Editions du Centre de Psychologie Appliquée.

Weiss, H., Stern, B., and Goldberg, J. (1991). Post-traumatic migraine: chronic migraine precipitated by minor head or neck trauma. Headache 31, 451-456. doi: 10.1111/j.1526-4610.1991.hed3107451.x

Whitaker, H. A. (1982). "Foreign accent syndrome," in Neuropsychology and Cognition: NATO Advanced Study Institute Series, eds R. N. Malatesha and L. C. Hartlage (The Hague: North Atlantic Treaty Organisation), 168-207.

Zazzo, R. (1974). Metody Psychologicznego Badania Dzieckat. II. Waszawa: Pantswowe Zaktady Wydawnictw Lekarskich.

Zwaardemaker, H., and Eijkman, L. P. H. (1928). Leerboek der Phonetiek. Inzonderheid met Betrekking tot het Standaard-Nederlands. Haarlem: De erven F. Bohn.

Conflict of Interest Statement: The authors declare that the research was conducted in the absence of any commercial or financial relationships that could be construed as a potential conflict of interest.

Copyright (c) 2016 Keulen, Verhoeven, De Page, Jonkers, Bastiaanse and Mariën. This is an open-access article distributed under the terms of the Creative Commons Attribution License (CC BY). The use, distribution or reproduction in other forums is permitted, provided the original author(s) or licensor are credited and that the original publication in this journal is cited, in accordance with accepted academic practice. No use, distribution or reproduction is permitted which does not comply with these terms. 